\title{
PEMBERSIHAN JARINGAN PIPA FLUIDISASI
}

\author{
Risda Gracia Iwanggin ${ }^{\mathrm{a}}$, Hendrik Pristianto ${ }^{\mathrm{b}}$ \\ ${ }^{a, b}$ Program Studi Teknik Sipil Universitas Muhammadiyah Sorong \\ Jalan Pendidikan No 27 Kota Sorong, Propinsi Papua Barat \\ Email : Risdha1098@gmail.com
}

\begin{abstract}
ABSTRAK
Metode fluidisasi adalah alternatif baru pengerukan pada pengelolaan lingkungan pantai. Hingga saat ini, metode fluidisasi belum menunjukkan kinerja yang memadai akibat masih adanya kelemahan dalam sistem. Penelitian ini bertujuan memahami permasalahan tersebut dan mendapatkan solusi perbaikannya. Penelitian meliputi kajian teoritis dan eksperimen terhadap karakteristik fluidisasi termasuk kebutuhan debit dan tinggi tenaga untuk fluidisasi, penyumbatan lubang dan solusinya serta kinerja pembentukan alur. Kebutuhan tekanan dan debit fluidisasi dirumuskan secara teoritis dari criteria kecepatan minimum fluidisasi (Richardson, 1971) dengan menggunakan hukum kontinuitas dan keseimbangan gaya pipa fluidisasi PVC 2". Eksperimen dilakukan untuk mempelajari mekanisme dan proses fluidisasi jet vertikal dan horisontal, pengaruh arah jet terhadap parameter hidraulik fluidisasi dan sistem kerja lubang perforasi untuk endapatkan solusi permasalahan penyumbatan.
\end{abstract}

Kata Kunci :Jaringan Pipa, pipa Fluidisasi, pembersihan jarangan pipa 


\section{BAB I \\ PENDAHULUAN}

\section{Latar Belakang}

Sejak tahun 1940, teknik fluidisasi sudah dikenal dan telah menjadi bagian terintegral dalam bidang teknik kimia dan industri. Teknik fluidisasi digunakan dalam proses penyulingan minyak, pembakaran batubara, industri plastik, proses pemindahan panas dan massa seperti pengeringan makanan, dll. (Balcony, 2002). Penggunaan fluidisasi sebagai metode pembersihan saringan pasir dimulai sejak tahun 1960an. Amirtharajah (1970), Amirtharajah dan Cleasby (1972), Cleasby dan Fan (1981) dalam Weisman, Lennon dan Robert (1988) melakukan optimalisasi fluidisasi 1 dimensi untuk pembersihan filter secara efektif tanpa menghilangkan partikel pasir saringan itu sendiri. Beberapa tahun terakhir ini, kajian dan aplikasi teknologi fluidisasi telah mengalami perkembangan yang inovatif khususnya pada pengelolaan lingkungan pantai. Kajian sistem fluidisasi ke arah teknologi pemeliharaan alur telah dilakukan sejak 1977 yang dirangkum oleh Weisman dan Lennon (1994). Hasil penelitian ini telah diaplikasikan untuk pemeliharaan alur pelabuhan di Ana Maria Florida (1986) dan sebagai system tambahan pada proyek sand by passing di Oseanside California (1991). Penelitian lanjutan dilakukan di Indonesia sejak tahun 2000 hingga saat ini. Teknik fluidisasi adalah metode baru pengerukan yang relatif lebih murah, praktis dan ramah lingkungan. Cara kerja fluidisasi adalah memanfaatkan gaya yang ditimbulkan oleh jet air dari pipa berlubang banyak (fluidizer pipe) di dasar sedimen untuk mengangkat dan mengagitasi endapan sedimen dan selanjutnya diangkut oleh aliran yang ada ke daerah yang lebih rendah. Meskipun sistem fluidisasi telah dikaji selama 15 tahun seperti dirangkum oleh Weisman and Lennon (1994), namun dalam penerapannya pada alur marina Anna Maria di Florida (1986) dan pemompaan pasir di Oceanside California (1991), sistem mengalami penyumbatan (clogging) dan berhenti beroperasi (Weisman, 2003). Kasus ini menjadi salah satu petunjuk bahwa permasalahan sistem masih perlu dikaji secara lebih komprehensif terutama pada aspek hidrauliknya. Lingkup kajian dalam penelitian disertasi ini meliputi mekanisme fluidisasi, faktor-faktor yang berpengaruh pada kebutuhan debit dan tinggi tenaga fluidisasi, mekanisme penyumbatan (clogging) lubang dan solusinya serta kinerja pembentukan alur oleh aliran gravitasi. Minimnya referensi teoritis juga menjadi kendala dalam penyusunan disain sistem fluidisasi khususnya untuk aplikasi pada pemeliharaan alur. 


\section{Tujuan Penelitian}

tekanan yang dibutuhkan untuk membersihkan sedimen pada pipa dan mendapatkan pemahaman yang lebih luas tentang mekanisme, proses danparameter fluidisasi sedimen dasar.

\section{Metode}

Lokasi studi

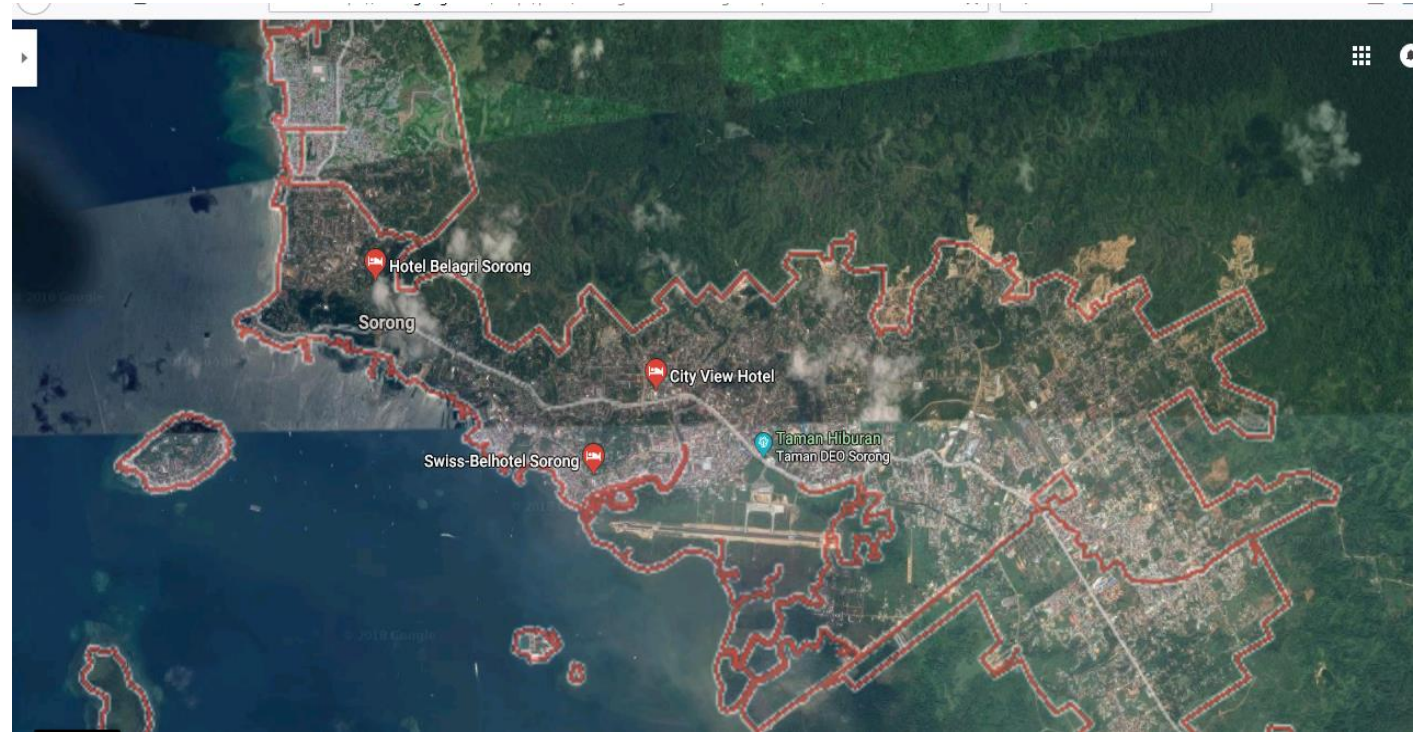

Gambar 1. Lokasi studi

\section{Tahap Penyusunan Artikel}

\section{Penentuan tema}

2. Penelusuran artikel yang bersesuaian dengan tema yang di ambil melalui google schoral.

3. Analisa kompratif terhadap artikel yang di dapatkan dari google schoral.

4. Membuat kesimpulan untuk menjawab tujuan penulisan artikel. 


\section{HASIL DAN PEMBAHASAN}

1. Menurut Pristianto, H. (2018) yang meniliti tentang Sistem Pengurasan Untuk Pembersihan Pipa Fluidisasi, kesimpulan yang dapat di ambil dari uraian ini adalah:

a. kebutuhan tekanan untuk membersihkan sedimen adalah semakin kecil kecepatan aliran dan semakin tingginya sedimen dalam pipa menurunkan nilai rerata gradien tekanan pada pipa horisontal, sedangkan pada pipa vertikal terjadi peningkatan nilai rerata gradien tekanannya.

b. terhadap waktu pengurasan sedimen dalam pipa fluidisasi adalah bahwa durasi pengurasan akan semakin singkat apabila koefisien kecepatan flushingnya meningkat. dalam pipa.

2. Menurut Dewi, T. K., Mandasari, K., \& Pratiwi, L. D. (2016) ) yang meniliti tentang PENGARUH METODA DISTRIBUSI DAN LAJU ALIR UDARA PADA PROSES PENCUCIAN KATALIS ZEOLIT SECARA FLUIDISASI. Jurnal Teknik Kimia, 22(1) kesimpulan yang dapat di ambil dari uraian ini adalah:

a. Waktu yang dibutuhkan agar terjadi fluidisasi sempurna berbanding lurus dengan laju alir udara pada jenis distributor yang digunakan.

b. Waktu penetralan zeolit dengan laju alir udara $2 \mathrm{Lpm}$ lebih pendek dibandingkan dengan laju alir udara $1 \mathrm{Lpm}$ dan $3 \mathrm{Lpm}$. 3) Pada distributor 1 (tunggal) waktu yang dibutuhkan untuk menetralkan zeolit lebih pendek dibandingkan dengan distributor 2 (ganda) dan distributor 3 (melingkar). 4) Waktu fluidisasi sempurna terbaik pada penelitian ini adalah pada penggunan distributor tunggal dengan laju alir udara $3 \mathrm{Lpm}$, dan waktu penetralan terbaik adalah pada penggunaan distributor tunggal dengan laju alir udara $2 \mathrm{Lpm}$.

\section{KESIMPULAN}

Kesimpulan yang dapat di ambil dari materi di atas adalah pada pipa fluidisasi dibutuhkan pengurasan dan pencucian sedimen dalam pipa fluidisasi sesuai kebutuhan tekanan. Dan lamanya waktu dalam pengurasan dan pencucian fluidisasi di perhatikan karena pengaruh durasi mempengaruhi koefisien kecekpatan tekanan dalam pipa.

\section{REFERENSI}

1. Pristianto, H. (2010, October 6). SISTEM PENGURASAN UNTUK PEMBERSIHAN PIPA FLUIDISASI. http://doi.org/10.17605/OSF.IO/TAQ8H.

2. Dewi, T. K., Mandasari, K., \& Pratiwi, L. D. (2016). PENGARUH METODA DISTRIBUSI DAN LAJU ALIR UDARA PADA PROSES PENCUCIAN KATALIS ZEOLIT SECARA FLUIDISASI. Jurnal Teknik Kimia, 22(1). 